\title{
Empirical Evidence on the Demand for Carve-Outs in Employment Group Mental Health Coverage
}

\author{
David S. Salkever* and Judith A. Shinogle \\ Department of Health Policy and Management, The Johns Hopkins University, Hampton House, Room 429, 624 N. Broadway, Baltimore, MD 21205,
}

\begin{abstract}
Background and Aims of Study: The use of specialized behavioral health companies to manage mental/health benefits has become widespread in recent years. Recent studies have reported on the cost and utilization impacts of behavioral health carve-outs. Yet little previous research has examined the factors which lead employer-based health plans to adopt a carve-out strategy for mental health benefits. The examination of these factors is the main focus of our study. Our empirical analysis is also intended to explore several hypotheses (moral hazard, adverse selection, economies of scale and alternate utilization management strategies) that have recently been advanced to explain the popularity of carve-outs.

Methods: The data for this study are from a survey of employers who have long-term disability contracts with one large insurer. The analysis uses data from 248 employers who offer mental health benefits combined with local market information (e.g. health care price proxies, state tax rates etc), state regulations (mental health and substance abuse mandate and parity laws) and employee characteristics. Two different measures of carve-out use were used as dependent variables in the analysis: (1) the fraction of health plans offered by the employer that contained carve-out provisions and (2) a dichotomous indicator for those employers who included a carve-out arrangement in all the health plans they offered.

Results: Our results tended to support the general cost-control hypothesis that factors associated with higher use and/or costs of mental health services increase the demand for carve-outs. Our results gave less consistent support to the argument that carveouts are demanded to control adverse selection, though only a few variables provided a direct test of this hypothesis. The role of economies of scale (i.e., group size) and the effectiveness of alternative strategies for managing moral hazard costs (i.e., HMOs) were confirmed by our results.

Discussion: We considered a number of different hypotheses concerning employers' demands for mental health carve-outs and found varying degrees of support for these hypotheses in our data. Our results tended to support the general cost-control hypothesis that factors associated with higher use and/or costs of mental health services increase the demand for carve-outs.
\end{abstract}

Limitations: Our database includes a small number of relatively

* Correspondence to: David S. Salkever, Department of Health Policy and Management, The Johns Hopkins University, Hampton House, Room 429, 624 N. Broadway, Baltimore, MD 21205, USA

Email address: dsalkeve@jhsph.edu

Contract grant sponsor: UNUM

Contract grant sponsor: The National Institute of Mental Health

Contract grant number: $\mathrm{MH}-43703$ large employers and is not representative of employers nationally. Our selection criteria, concerning size and the requirement that some employees are covered by LTD insurance, probably resulted in a study sample that offers richer benefits than do employers nationally. Our employers also report a higher percentage of salaried employees relative to the national data. Another deficiency in the current study is the lack of detailed information on the socio-demographic and behavioral characteristics of covered employees. Finally, the cross-sectional nature of our analysis raises concerns about susceptibility of our findings to omitted variables bias.

Implications for Further Research: Research with more information on covered employee characteristics will allow for a stronger test of the general hypothesis that factors associated with a higher demand for services are also associated with a higher demand for carve-outs. Also, future analyses that capture the experience of states that have recently passed mandate and parity laws, and that use pooled data to control for omitted variables bias, will provide more definitive evidence on the relationship between these laws and carve-out demand. Copyright ( 2000 John Wiley \& Sons, Ltd.

Received 10 January 2000; accepted 21 June 2000

\section{Introduction}

The use of specialized behavioral health companies to manage mental health benefits has become widespread in recent years. This strategy of separating out responsibility for mental health benefits corresponds to the general definition of carve-outs ${ }^{1}$ as the "use (of) administrative or legally separate organizations to provide health care services for particular conditions, procedures, diseases, or groups of patients'.* The carve-out strategy can be implemented in various ways. Health plans may subcontract with behavioral health companies or the latter may contract directly with the group of insured enrollees (or their employer). The scope of functions for the carve-out provider may range from simply providing utilization management services all the way to provider network formation and management.

* The American Managed Behavioral Health Association used a similar definition of mental health and substance-abuse carve-outs: 'a management approach where a defined category of health benefits are placed under the supervision of experts who understand that category of services and are better prepared to manage the associated costs'. ${ }^{2}$ 
The scope of the carve-out may be also defined in terms of a population of patients with a particular disorder or set of disorders, or in terms of specified types of treatment. Financial provisions of carve-out contracts also vary in the degree to which the behavioral health companies assume financial risk. $^{3}$

In view of the wide variations within the broad concept of carve-out arrangements, it is difficult to arrive at definitive figures on the market penetration of these arrangements; but recent estimates confirm that, regardless of the precise definition, carve-outs are becoming a major feature of the mental health marketplace. Buck and Umland examined a convenience sample of 171 employers and found that onefifth of the employers carved out mental health and substance abuse (MHSA) from at least one of the medical plans offered. ${ }^{4}$ The percentage of employers utilizing carve-out for MHSA benefits grew from 7 percent in 1993 to 19 percent in 1994 according to a survey by Foster Higgins. ${ }^{5}$ More recent data suggest continued growth. The HayGroup found that 20 percent of the firms they surveyed in 1999 provided inpatient and outpatient mental health benefits through a carved out arrangement. ${ }^{6}$ Another recent employer survey found that 24 percent of covered workers in 1999 are in firms that carve out mental health benefits, ${ }^{7}$ while a survey of Fortune 500 firms reported an increase in the percentage of firms contracting directly with carve-outs from 27 percent in 1993 to 39 percent in $1997 .{ }^{8}$

A number of recent studies have reported on or reviewed the cost and utilization impacts of behavioral health carveouts..$^{3,9,10} \mathrm{We}$ are not aware, however, of any previous empirical research that has examined the factors which lead employer-based health plans to adopt a carve-out strategy for mental health benefits. The examination of these factors is the main focus of our study. Our empirical analysis is also intended to test several hypotheses that have recently been advanced to explain the popularity of carve-outs. We begin with a brief discussion of these hypotheses and place them in the context of a conceptual model of employers' mental health benefit choices for their employees. We then present descriptive information on the employers in our study, the generosity of the mental health benefits they provide and their use of carve-outs. The remaining sections of the paper present the variables and methods used in our multiple regression analyses of the demand for carve-outs and the results of these analyses. We conclude with a brief summary and discussion of assumptions, limitations and implications for future research.

\section{Conceptual Context and Major Hypotheses}

\section{Employer Decision-Making}

Employment groups' decisions about carve-outs are part of their larger health benefit choice decision process. The literature on that process views the employer decision-maker as choosing the profit-maximizing scope and level of health benefits based on (1) the preferences of her employees, (2) the costs of benefits, and (3) the market-determined value of compensation which she must offer to attract and retain her workers. A formal model of this process has been developed by Dowd and Feldman. ${ }^{11}$ An interesting prediction of their model is that firms whose workers face a higher risk of illness will tend to provide more complete insurance coverage.

Recent empirical studies have used this general framework to specify insurance demand models that include the following sets of factors as predictors of insurance coverage: (a) employee characteristics that are related to risk levels or benefit preferences (e.g., age, gender, education), (b) proxies for variations in insurance loading costs (e.g., group size) and the value of the insurance tax subsidy (e.g., state tax rates), (c) the price of covered benefits (e.g., hospital prices) and (d) state regulatory requirements (e.g., benefit mandates). Results for overall insurance demand (i.e., the probability of offering employees coverage) by small firms have been reported in three recent studies. ${ }^{12-14}$ All three studies found that firm size as measured by number of employees was strongly and positively related to demand for insurance. Only the first of these studies reported significant tax-subsidy effects. The latter two studies found significantly negative effects of state mandates. Income and other employee characteristics were not generally significant although the significant controls for industry type (e.g., manufacturing versus agriculture) in these studies presumably reflect differences in worker preferences. Only the recent study by Morrisey and Jensen ${ }^{15}$ reported empirical results specifically for mental health coverage (outpatient). This study replicated the previously cited result for state benefit mandates, but found only one other significant predictor of insurance demand, firm size, whose coefficient was unexpectedly negative. Morrisey and Jensen ${ }^{15}$ also reported results for alcohol abuse coverage that paralleled their outpatient mental health coverage findings. Another study, by Gentry and Peress, ${ }^{16}$ examined the percentages of bluecollar and white-collar workers offered drug and alcohol treatment coverage in an area (city/region). Results for the two groups of workers were quite similar. They found that workers' years of education and the fraction of manufacturing workers in the area who belong to a union were significantly positive predictors of coverage.

\section{Demand for Carve-Outs, Moral Hazard and Adverse Selection}

Applying this same general conceptual framework, we view the choice of a carve-out arrangement as being made simultaneously with the choice of mental health benefits and general health benefits. Frank et al. ${ }^{17}$ have identified two primary functions for carve-outs. First, managed behavioral health companies have special expertise in controlling the costs of 'moral hazard', which are incurred when enrollees use services of marginal mental health benefit because the out-of-pocket costs of these covered services are low.

Second, an employer with a heterogeneous workforce may wish to offer employees a range of benefit plans (for 
either general health and/or mental health) consistent with the variations in workers' preferences for insurance or tolerance for financial risk. An employer's ability to offer multiple plan choices, however, may be constrained by the problem of adverse selection, that is, the tendency of 'bad risks' to join the plans with the most generous benefits. The most problematic result of adverse selection is the unsustainability of benefit plans with very limited consumer cost-sharing in a multiple-plan system. Selection of 'bad risks' into these plans leads to higher and higher premiums and lower and lower enrollments until the plan is no longer offered. The result is that plans with more generous coverage will simply be unavailable and the preferences of employees who would join such plans will not be reflected in the menu of plan choices. ${ }^{18,19}$ Several studies have reported empirical examples of this phenomenon (i.e., the "premium death spiral'). ${ }^{19,20}$

Employers can use carve-outs to alleviate this adverse selection problem in two ways. First, the affordability of a plan with very limited consumer cost sharing can be maintained by effective utilization management. (Cutler and Zeckhauser ${ }^{19}$ discuss a specific example of using utilization management of general health services to control adverse selection in the Massachusetts GIC health plan for government employees.) As noted above, in the case of mental health services, carve-outs may be especially good at performing this utilization management function.*

In addition, the employer can use the same carve-out arrangement across all offered plans and provide uniform coverage and utilization management for services that are particularly susceptible to adverse selection problems, such as mental health care. ${ }^{21}$ This would allow the employer to satisfy diverse employee preferences for non-mental-health services or financial risk, by offering a variety of benefit packages, while preventing adverse selection based on mental health risks.

\section{General Research Hypotheses}

These observations lead to three general hypotheses that we will explore. First, management of moral hazard costs will be more important for employee groups as the cost level of their desired mental health benefits increases. Thus, the attractiveness of carve-outs depends upon the preferences for mental health benefits and the costs of the mental health benefits offered. The factors that predict more generous coverage or higher coverage costs for mental health benefits should also predict a higher demand for carve-outs.

Second, factors that influence the extent of the adverse selection problem, such as heterogeneity of preferences within the group of covered employees and state benefit mandate laws, should also influence the demand for carve-outs.

\footnotetext{
* In other words, the fact that carve-outs are good at controlling moral hazard also implies they are helpful in reducing adverse selection problems in a multi-plan context, even if not all of the available plans include the carve-out.
}

Third, we expect that the availability of alternative cost control mechanisms that could substitute for carve-outs will reduce the demand for carve-outs.

Specific examples of predictor variables and hypotheses that illustrate these three general hypotheses are discussed below.

\section{Employers, Mental Health Benefits and Carve-Outs}

\section{Employer Characteristics and Data Collection Methods}

In the spring of 1996, we identified a study population of 1433 employers who had active long-term disability (LTD) insurance policies with UNUM, a major provider of disability insurance. Selection criteria included: (1) being a UNUM customer over the preceding three years, and (2) having at least 300 covered lives on the LTD policy at any time during that three year period. These employers received a mailed questionnaire in the latter half of 1996 concerning the benefits they provided to their employees and their disability management practices and programs. In addition, employers were asked to send in summary plan descriptions (SPDs) for each of the health plans they offered to their employees. After the mailing of the survey instrument, employers also received follow-up calls to encourage responses and to answer any questions about the survey. SPDs were received from 241 employers; an additional nine employers declined to send the SPDs but filled out and sent in detailed abstracting forms (which were mailed to them after telephone follow-up contacts) that described their health plans. Thus, the total database for this analysis is the 577 health plans, offered by these 250 employers, on which detailed information was obtained. (Since the overall response rate was low, as is often the case in employer mail surveys, ${ }^{13}$ we have carefully reviewed evidence of possible respondent bias. This evidence, which is discussed in Appendix A, strongly suggests that respondent bias is not a serious threat to the internal validity of our conclusions.) Of these 250 respondents, two were dropped from the analysis because they did not offer mental health benefits. Table 1 presents characteristics of the 248 employers in this study. Two characteristics are especially noteworthy: (1) they are relatively large, with 50 per cent employing more than 773 employees, and (2) their workforce is primarily salaried. (In contrast, according to the March 1996 Current Population Survey, 60.8 per cent of all employed persons were paid on an hourly basis.)

\section{Classifying Health Plans and Measuring Mental Health Benefit Generosity}

Information was obtained on 573 health plans from 248 employers (an average of 2.31 plans per employer). Each plan was classified into one of three principal types: health maintenance organizations (HMO), preferred provider 
Table 1. Employer characteristics

\begin{tabular}{lr} 
Total employees & \\
mean & 1775.84 \\
median & 773.00 \\
Percentage salaried employees $^{\mathrm{a}}$ & $53.66 \%$ \\
Percentage union employees $^{\mathrm{a}}$ & $12.63 \%$ \\
& \\
Distribution by region $^{\text {East Central }}$ & \\
Middle/South Atlantic & $27.42 \%$ \\
New England & $34.27 \%$ \\
Mountain/Pacific & $4.03 \%$ \\
West Central & $16.94 \%$ \\
& $17.34 \%$ \\
Distribution by industry: & \\
Finance, insurance, real estate & \\
Manufacturing & $14.52 \%$ \\
Services & $25.00 \%$ \\
Retail/wholesale trade & $47.18 \%$ \\
Other & $5.24 \%$ \\
\hline
\end{tabular}

aCalculated on those firms who reported information $(n=224)$.

organizations (PPO) or fee-for-service plans (FFS).* Plans were also classified in terms of having or not having a mental health carve-out. $\dagger$ The plans were fairly evenly divided among the three plan types: $28.77 \%$ were classified as FFS, $38.37 \%$ were HMOs and $34.64 \%$ were PPOs.

Table 2 presents further information about the types and numbers of plans offered by employers. Many employers only offered one health plan, $33.87 \%$, but a large percentage, $27.82 \%$, offered more than four health plans. Overall, $14.11 \%$ of employers carved out mental health from all their health plans while $25.81 \%$ carved out mental health from at least one health plan. Limiting our comparison to employers offering more than one health plan, we also observe that of the 47 employers with multiple health plans

\footnotetext{
* To classify plans as HMOs or PPOs, we first examined each plan's SPD or plan abstract to see whether these documents described the plan as an HMO. We also reviewed information on the plans to verify that all HMOs and PPOs in fact included restrictions on the providers from whom treatment could be sought under 'in-network' or most favorable benefit provisions. To verify distinctions between HMOs and PPOs, we examined the cost sharing provisions under each plan for routine ambulatory care (e.g. office visits, physical examinations). HMOs that imposed coinsurance requirements for these services were reclassified as PPOs. (This happened in three cases.) PPOs that used small copayments rather than coinsurance for routine ambulatory care were reclassified as HMOs. (This happened in one instance.)

$\dagger$ Plans were coded as having a mental health carve-out if their benefit description identified a different insurer or organization as being the contact for authorization, review, coordination and administration of mental health benefits.

\$ Note also that we did not distinguish between 'in-plan' and 'out-of-plan' carve-outs. This distinction would be most important if the 'in-plan' carveout were simply a 'make versus buy' decision of the health plan that was of no consequence to the employer. While such an assumption may be valid for, say, the choice of internal versus contracted janitorial services in a clinic, it is probable that the choice of a carve-out affects the willingness of the employer to offer the plan. Thus, assuming that the attributes of the offered plans are in fact reflective of the employer/purchaser's preferences, the 'in-plan' versus 'out-of-plan' distinction is arguably not significant. This assumption seems consistent with the competitive nature of the market for health plans at the time represented by our data.
}

who reported any carve-outs only 22 carved out all plans. These figures are similar to data from other surveys., ${ }^{4,6-8}$

We computed the fraction of plans offered by each employer that fell into each of the three plan types; the averages of these fractions across employers are shown in Table 2. (We could not compute enrollment-weighted averages since enrollment data by plan were not available.) The type of plan offered varied depending on the number of plans the employer offered. For employers who offered two or less health plans, PPOs were the most common plan offered. If the employer offered three health plans, the plans were almost equally divided between HMOs (33.12\%), PPOs $(35.47 \%)$ and FFS (31.41\%). For employers that offered four or more health plans, the most common plan type was HMO (41.84\%).

We computed three variables describing mental health benefit generosity (i.e., simulated coverage percentages) corresponding to outpatient services (MHOPCOV), inpatient services (MHIPCOV) and inpatient plus outpatient services (MHCOV).* These variables were computed by applying specific plan provisions (relating to deductibles, coinsurance, copayments and limits) to 100000 random draws from a utilization distribution based on (1) published mental health utilization data, ${ }^{22,23}$ (2) tabulations for non-elderly respondents from the 1993 US National Health Interview Survey, and (3) unit price figures for inpatient days and outpatient visits (general health and mental health). Inpatient prices per day for general health and mental health care, respectively, were drawn from the US Census Bureau ${ }^{24}$ and from Leslie and Rosenheck. ${ }^{25}$ Outpatient price per visit for general health care is from the American Medical Association; ${ }^{26}$ the corresponding mental health price is from a price list of a large managed behavioral health care provider. $\dagger$

We then examined differences in mental health benefit generosity by plan type (Table 3). We tested these differences using $t$-tests with a Scheffe ${ }^{27}$ adjustment for multiple tests and found several significant results. PPO plans had higher simulated coverage percentages for both total and outpatient expenditures in comparison to FFS plans, and they also covered more simulated inpatient expenditures than HMO plans. FFS plans covered a significantly higher percentage of simulated inpatient expenditures than did HMO plans but the reverse was true for outpatient expenditures.

We also examined health plan type by carve-out status (Table 4). Almost $20 \%$ of all plans included carve-out provisions but the use of carve-outs varied significantly by type of plan. FFS plans were generally less likely to include carve-out provisions. Finally, in Table 5 we examined differences in mental health benefit generosity by carve-out status. Testing for the differences in means, we found that simulated coverage for total expenditures and outpatient

\footnotetext{
* Our measures of generosity relate only to cost-sharing and coverage of financial risk; we did not incorporate any supply-side or plan rationing efforts in these measures.

$\dagger$ Note that our benefit generosity measures were based on a fixed distribution of expenditures that was the same for all plans. We did not attempt to account for demand responses to changes in cost sharing provisions.
} 


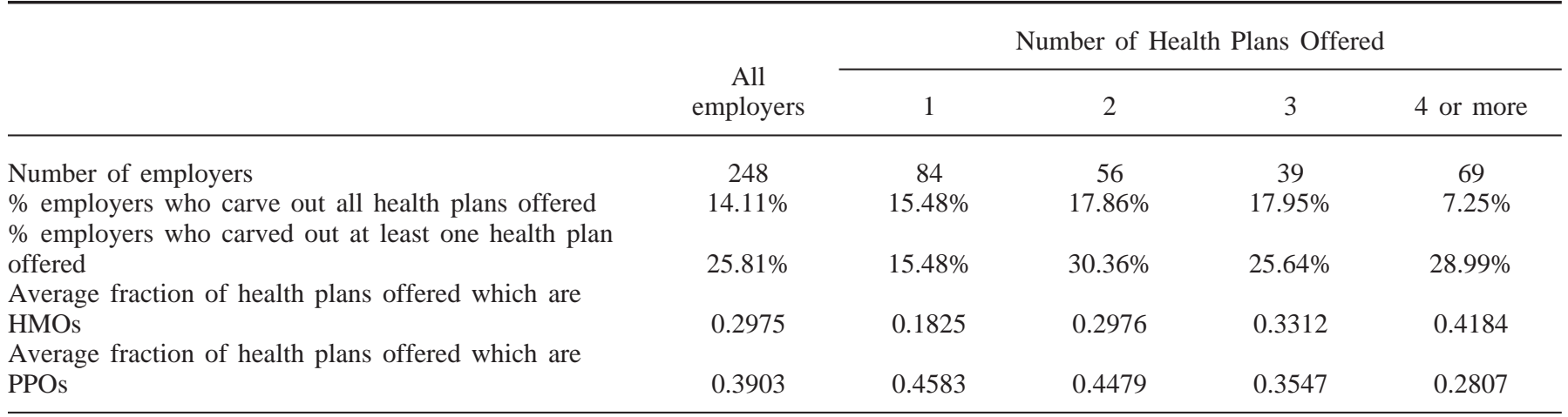

Table 3. Mean generosity of mental health benefits by plan type

\begin{tabular}{lccc}
\hline & FFS & HMO & PPO \\
\hline$n$ & 162 & 216 & 195 \\
$\begin{array}{l}\text { Simulated percentage of } \\
\text { total mental health } \\
\text { expenditures covered }\end{array}$ & $0.590^{\mathrm{a}}$ & 0.624 & $0.656^{\mathrm{a}}$ \\
$\begin{array}{l}\text { Simulated percentage of } \\
\text { outpatient mental health } \\
\text { expenditures covered }\end{array}$ & $0.585^{\mathrm{a}, \mathrm{b}}$ & $0.633^{\mathrm{b}}$ & $0.657^{\mathrm{a}}$ \\
$\begin{array}{l}\text { Simulated percentage of } \\
\text { inpatient mental health } \\
\text { expenditures covered }\end{array}$ & $0.642^{\mathrm{b}}$ & $0.535^{\mathrm{b}, \mathrm{c}}$ & $0.640^{\mathrm{c}}$ \\
\hline
\end{tabular}

${ }^{a}$ FFS is significantly different from PPO at $p<0.05$.

${ }^{\mathrm{b}} \mathrm{FFS}$ is significantly different from HMO at $p<0.05$.

${ }^{\mathrm{c}} \mathrm{HMO}$ is significantly different from PPO at $p<0.05$.

Table 4 . Health plan type by carve-out status

\begin{tabular}{lcc}
\hline & \multicolumn{2}{c}{ Carve-out status $^{\mathrm{a}}$} \\
\cline { 2 - 3 } Plan type & No & Yes \\
\hline Percentage of plans & $80.80 \%$ & $19.20 \%$ \\
FFS & 0.901 & 0.099 \\
HMO & 0.778 & 0.222 \\
PPO & 0.764 & 0.236 \\
\hline
\end{tabular}

${ }^{\mathrm{a}} \chi^{2}$ test significant with $p$-value $<0.01$.

Table 5. Mean generosity of mental health benefits by carveout status

\begin{tabular}{llc}
\hline & \multicolumn{2}{c}{ Carve-out status } \\
\cline { 2 - 3 } & \multicolumn{1}{c}{ No } & Yes \\
\hline $\begin{array}{l}\text { Simulated percentage of total mental } \\
\text { health expenditures covered }\end{array}$ & $0.609 * * *$ & 0.691 \\
$\begin{array}{l}\text { Simulated percentage of outpatient } \\
\text { mental health expenditures covered }\end{array}$ & $0.611^{* * *}$ & 0.697 \\
$\begin{array}{l}\text { Simulated percentage of inpatient } \\
\text { mental health expenditures covered }\end{array}$ & 0.593 & 0.634 \\
\hline
\end{tabular}

$* * * t$-test significant with $p$-value $<0.0001$. expenditures was significantly more generous for plans with carve-outs.

\section{Multivariate Analysis}

\section{Dependent Variables}

Means and standard deviations for all dependent and explanatory variables used in the multivariate analysis are presented in Table 6.

Two different measures of carve-out use were used as dependent variables in the analysis: (1) the fraction of health plans offered by the employer that contained carve-out provisions (PCTMHCARVE) and (2) a dichotomous indicator for those employers who included a carve-out arrangement in all the health plans they offered (CARVEALL). Analysis of PCTMHCARVE includes data for all employers; analysis of CARVEALL is restricted to the 164 employers who offered more than one health plan. Note that the implications of these two different dependent variables for hypothesis tests about control of moral hazard costs and adverse selection are not parallel. The inclusion of all health plans under carve-outs (CARVEALL $=1$ ), and especially under one single carve-out arrangement, is especially important for controlling adverse selection since this greatly reduces or eliminates differences among plans in the management of care.* From the cost-control perspective, however, there is no particular reason to believe that an increase in PCTMHCARVE from, say, 0.75 to 1 is more important than an increase of the same magnitude from 0.5 to 0.75 .

\section{Predictor Variables and Hypotheses}

Predictor variables included in this study fall into three main categories: worker characteristics, firm characteristics and state/area characteristics. (Data sources for these variables are described in Appendix B.)

Measures of state mandate and parity laws were included as a differential test of the moral hazard and adverse

\footnotetext{
* Of the 164 employers offering more than one plan, 22 reported carveouts for all plans offered. Of these 22 , all but one used the same carveout provider for all plans.
} 
Table 6. Variable definitions and summary statistics

\begin{tabular}{|c|c|c|c|}
\hline Variable & Definition & Mean & Std Dev. \\
\hline CARVEALL & $=1$ if all the firm's health plans carve out mental health & 0.1411 & 0.3489 \\
\hline CARVEALL & CARVEALL for those firms who offer more than one health plan, $n=164$ & 0.1341 & 0.3419 \\
\hline PCTMHCARVE & Fraction of the firm's health plans that carve out mental health & 0.1878 & 0.3565 \\
\hline EMPLOYEES & Total number of employees & 1776 & 2759 \\
\hline PCTSAL $^{\mathrm{a}}$ & Fraction of the firm's employees who are salaried & 0.5366 & 0.3056 \\
\hline SALMISS & $=1$ if salaried unknown & 0.0968 & 0.2962 \\
\hline UNIONSAL & $=1$ if firm has union salaried employees & 0.0726 & 0.2600 \\
\hline AGE & Mean age of employees in industry & 39.8013 & 0.4791 \\
\hline PCHMO & HMO enrollment per capita by state & 0.2014 & 0.1007 \\
\hline AAPCC96 & Average adjusted per capita costs for Medicare elderly by county in 1996 & 391.7889 & 74.9154 \\
\hline ALC94 & State per capita alcohol (all types) consumption in gallons, 1994 & 2.2079 & 0.3568 \\
\hline UNEMP95 & State unemployment rate, 1995 & 5.5109 & 1.1780 \\
\hline MTAX94 & Marginal tax rate for married couple with two dependents, 1994 & 0.2006 & 0.0282 \\
\hline MANDATE & $\begin{array}{l}=1 \text { if state had mandates for mental health, drug abuse and alcohol abuse } \\
\text { coverage in } 1995 \text { and the firm had fewer than } 1000 \text { employees }\end{array}$ & 0.0685 & 0.2532 \\
\hline PARITY & $\begin{array}{l}=1 \text { if state had mental health parity laws in } 1995 \text { and the firm had fewer than } \\
1000 \text { employees }\end{array}$ & 0.0444 & 0.2063 \\
\hline
\end{tabular}

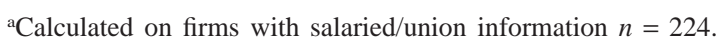

selection hypotheses. On the one hand, the positive effect of these laws on the generosity of mental health benefits implies an increased demand for cost control via carve-outs. On the other hand, for employers who offer multiple plan options, these laws may also reduce the possible range of variation in benefits among plan options by setting a floor on the lowest options in terms of mental health coverage. As a result, high option plans will be less subject to adverse selection problems, and there will be less need to rely on direct utilization management controls to maintain the viability of high-option plans. This should impact negatively on the demand for mental health carve-outs.*

One can, however, imagine a situation in which a mandate or parity law could have a positive effect on carve-out demand as a means for controlling adverse selection. If an employer offered a high-option plan with generous health coverage but meager mental health coverage, and a lowoption plan with meager health coverage and generous mental health coverage, a mandate or parity law could compel expansion of mental health benefits for the highoption plan and perhaps increase the adverse selection against this plan. As an empirical matter, we suspect that the strong negative correlation of health benefit generosity and mental health benefit generosity assumed by this example

\footnotetext{
* It is conceivable that employers in this situation might attempt to offset the increased generosity of low-option plans, resulting from parity or mandate laws, by managing utilization in these plans more aggressively. Such a response would again imply a positive effect of parity and mandate laws on demand for carve-outs to control moral hazard costs rather than to control adverse selection. In this case, however, the purpose would be to control the costs of low-option plans so that employees would continue to have a wide range of plan choice.
}

rarely occurs.* Thus, we do not think it is warranted to interpret any observed positive effects of mandate or parity laws on the use of carve-outs primarily as responses to adverse selection concerns. $\dagger$

It should also be noted that because state mandate and parity laws only affect health insurance plans regulated by the state (i.e., plans with no ERISA exemption), we only set the mandate (or parity) variable equal to one if the firm was in a state that mandated coverage (or parity) and the firm had fewer than 1000 employees. $\ddagger$ (We also estimated models with alternative specifications of the interaction between state law dummies and the number of employees in the firm. Results from estimating these models are described below.)

We include three measures relating to worker or population characteristics to control for variations in the level of demand for services. White-collar workers are expected to demand more mental health services, ceteris paribus, than blue-collar workers because of differences in income and education level. ${ }^{29-31}$ Thus, firms with a higher percentage of salaried workers (PCTSAL) should be more likely to carve out mental health benefits to control the costs of their

\footnotetext{
* In our own data on employers offering multiple plan options, the correlation between mental health and general health benefit generosity is positive.

† Our discussion also here assumes that positive effects of parity or mandate laws on the average level of mental health demand in the employee group do not affect the extent of adverse selection among the plan options offered to that group. Further discussion of this assumption is provided in the next-to-last section of this paper.

$\ddagger$ The 1000-employee cut point is based on data from Uccello, ${ }^{28}$ showing that 75 per cent of firms with 1000 employees or more that offered health insurance were self-insured versus only 46 per cent self-insured for firms with 500 to 999 employees.
} 
mental health services use. The same logic implies that firms in industries with an older workforce will be more likely to use a carve-out because older workers demand more mental health services. ${ }^{30-32}$ Areas with higher alcohol consumption may demand more mental health services since alcoholism is often associated with other mental health problems. Also, firms often include substance abuse (including alcohol abuse treatment) in the mental health carve-out. Therefore, we would hypothesize that as the state per capita consumption of alcohol increases the firm is more likely to use a mental health carve-out.

Other firm characteristics that may influence the decision to carve out mental health include firm size and unionization. We expect that at least some portion of the administrative and contracting costs to carve out a benefit is fixed regardless of the number of employees. These fixed costs can be spread over more employees as the size of the firm grows. Thus we hypothesize that as the number of employees increases, the firm is more likely to report a mental health carve-out. Firms with union employees may demand more mental health benefits, thus increasing the employer's demand for a carve-out. Because over half of the employees in this data are salaried workers, our measure of unionization is a dummy variable that equals one if union salaried employees are present, and zero otherwise. We hypothesize that firms with unionized salaried employees are more likely to carve out mental health benefits.

Other measures of the economic environment of the area or state include HMO penetration, health care costs, marginal tax rates and the unemployment rate. If alternative cost control options, such as HMOs, are more effective in controlling moral hazard, we expect a lower demand for mental health carve-outs. Thus, when HMOs are more effective in capturing market share, as indicated by a higher percentage of the state population enrolled in HMOs (PCHMO), we expect the likelihood of carving out mental health benefits to be lower.*

Areas where unit mental health service costs are higher should, according to the cost-control hypothesis, show a higher demand for carve-outs. Since we have no price level measure for mental health care, we use as a proxy the local costs to Medicare for health care services (AAPCC96). The state marginal tax rate affects the price of benefits because employer-provided health benefits are non-taxed compensation. States with higher marginal tax rates will have a lower relative (after-tax) price for the benefit and thus employees should demand more generous coverage. According to the cost-control hypothesis, this should imply a higher demand for carve-outs; however, employees may also be less concerned with the excess costs of moral hazard (that carve-outs seek to control) when their marginal tax rate is higher, so the expected net effect of the tax rate variable is

\footnotetext{
* Since the employer is viewed as simultaneously deciding on carve-out arrangements and on offering HMO plans to employees, an explanatory variable measuring actual offering of HMO plans by the firm would be endogenous and a two-stage estimation procedure would fail for the lack of reasonable a priori exclusion restrictions.
}

unclear. In areas with high unemployment rates, prevailing compensation levels are presumably lower, ceteris paribus, and employer-provided fringe benefits are less generous. ${ }^{13}$ According to the cost-control hypothesis, this should reduce the demand for mental health carve-outs.

\section{Regression Methods}

The form of the estimated regression models varied between our two dependent variables. Since PCTMHCARVE was bounded by 0 and 1, we applied two-limit Tobit regression to the dependent variable. CARVEALL is a binary variable and was analysed in the context of a linear probability model and a logistic regression model. As noted above the regression on CARVEALL only included the 164 firms that offered more than one health plan.

\section{Results}

Table 7 presents results from the two-limit Tobit regressions on PCTMHCARVE. Three different models were estimated. Model one includes all variables of interest, model two deletes the marginal tax rate variable, and model three deletes the two variables with the lowest $t$-statistics in model two. In all three models, three explanatory variables are consistently significant with the expected signs: PCTSAL, EMPLOYEES and HMO. (Note that all $p$-values in Tables $\mathbf{7}$ and $\mathbf{8}$ are two tailed.) Results for the PARITY and MANDATE variables are not significant and are opposite in sign to the prediction of the adverse selection hypothesis. When PARITY is deleted, the positive MANDATE coefficient approaches significance. This pattern of results could be viewed as more favorable to the cost-control hypothesis than to the adverse selection hypothesis. On the other hand, with a relatively small study sample, one should not place too much weight on the absence of significantly negative coefficients for these variables.

Results for other variables (ALC94, AGE) are consistent in sign with the general cost-control hypothesis that greater demand for benefits leads to greater demand for carve-outs but are further from conventional significance levels. The most surprising result is the strongly positive coefficient for the state unemployment rate. One could speculate, however, that this result is also a product of increased demand for coverage because higher unemployment is associated with higher levels of mental health utilization. ${ }^{29}$ The coefficients of the union variable also have an unexpected (negative) sign and approach conventional significance levels.

Table 8 presents results for regressions on CARVEALL for the 164 firms that offered two or more health plans using (1) maximum-likelihood logistic regression and (2) a linear probability regression estimated by ordinary least squares (OLS). In the logistic regressions, the coefficient for PARITY was not identified because all eight data points with PARITY $=1$ reported CARVEALL $=0$. For both models, we report results with and without the marginal tax rate variable.

In general, results are quite similar to those reported for 
Table 7. Tobit models for percentage of plans with mental health carve-out

\begin{tabular}{|c|c|c|c|c|c|c|c|c|c|}
\hline \multirow[b]{2}{*}{ Variable } & \multicolumn{3}{|c|}{ Model one } & \multicolumn{3}{|c|}{ Model two } & \multicolumn{3}{|c|}{ Model three } \\
\hline & Coefficient & $t$ & $P>|t|$ & Coefficient & $t$ & $P>|t|$ & Coefficient & $t$ & $P>|t|$ \\
\hline PCTSAL & 2.3750 & 3.193 & 0.002 & 2.3927 & 3.202 & 0.002 & 2.4073 & 3.226 & 0.001 \\
\hline SALMISS & 0.7491 & 1.003 & 0.317 & 0.7483 & 0.999 & 0.319 & 0.7571 & 1.022 & 0.308 \\
\hline ALC94 & 0.8995 & 1.530 & 0.127 & 0.8029 & 1.386 & 0.167 & 0.8051 & 1.385 & 0.167 \\
\hline EMPLOYEES & 0.0002 & 2.235 & 0.026 & 0.0002 & 2.257 & 0.025 & 0.0002 & 2.249 & 0.025 \\
\hline UNIONSAL & -1.3035 & -1.609 & 0.109 & -1.3205 & -1.636 & 0.103 & -1.3083 & -1.639 & 0.102 \\
\hline АAPCC96 & 0.0005 & 0.192 & 0.848 & 0.0001 & 0.038 & 0.969 & & & \\
\hline HMO & -4.5483 & -1.908 & 0.058 & -3.5728 & -1.652 & 0.100 & -3.5553 & -1.653 & 0.100 \\
\hline AGE & 0.5808 & 1.324 & 0.187 & 0.5437 & 1.240 & 0.216 & 0.5377 & 1.231 & 0.220 \\
\hline PARITY & 0.3059 & 0.315 & 0.753 & 0.3139 & 0.321 & 0.748 & & & \\
\hline MANDATE & 0.9467 & 0.987 & 0.325 & 1.1174 & 1.175 & 0.241 & 1.2688 & 1.544 & 0.124 \\
\hline UNEMP95 & 0.3714 & 1.883 & 0.061 & 0.3797 & 1.912 & 0.057 & 0.3757 & 2.024 & 0.044 \\
\hline MTAX94 & 7.6289 & 1.034 & 0.302 & & & & & & \\
\hline CONSTANT & -30.9041 & -1.780 & 0.087 & -27.7801 & -1.571 & 0.118 & -27.4899 & -1.559 & 0.120 \\
\hline
\end{tabular}

PCTMHCARVE. PCTSAL and UNEMP95 show significantly positive coefficients while the negative coefficients for HMO and UNIONSAL are, respectively, highly significant and nearly significant at the 0.1 level. ALC94 and AGE have positive coefficients, as in Table 7, but the associated $p$-values are generally much lower (except for AGE in the OLS regressions). The estimated coefficients for MANDATE and AAPCC96 are again positive but insignificant, and once again there is no evidence of marginal tax rate effects. The two sharpest differences from the results in Table 7 are that EMPLOYEES is now clearly insignificant and, in the OLS regression, PARITY is strongly negative. The latter result provides some support to the adverse selection hypothesis.

A number of additional regression models were estimated to test the stability of the principal results reported here.* These included: (1) deleting additional variables with clearly insignificant coefficients from the regression models in Tables $\mathbf{7}$ and $\mathbf{8}$, (2) adding squared terms for variables such as EMPLOYEES and PCTSAL, (3) using a variable for the percentage of all employees unionized instead of UNIONSAL, (4) re-estimating the regressions in Table 7 using an ordered three-response logit model instead of twolimit Tobit and (5) re-estimating the logistic regressions in Table $\mathbf{8}$ as probit models with a selectivity correction. These modifications did not produce any substantial changes in our findings. $\dagger$

In addition, we re-estimated the models in Table 7 deleting the 84 employers who only offered one plan since adverse selection motives would presumably be irrelevant for these employers. The changes in results were not dramatic. The positive coefficient for ALC94 became more

\footnotetext{
* Results are available from the authors.

$\uparrow$ A quadratic relationship of PCTSAL to carve-out demand could be viewed as supporting the adverse selection hypothesis. Heterogeneity of employees would be expected to increase the potential importance of adverse selection for any employer, and it could be argued that heterogeneity is greatest for PCTSAL $=0.5$ and declines as PCTSAL approaches 0 or 1. Our results, however, provided no support to the hypothesis that PCTSAL has a nonlinear effect on carve-out demand.
}

significant ( $p$-values in the range 0.074 to 0.086 ) while the coefficients for EMPLOYEES were reduced in size and significance ( $p$-values in the range 0.086 to 0.105$)$. UNIONSAL became more significant ( $p$-values from 0.069 to 0.096 ) with little change in coefficient size; the same was true for HMO in models two and three. Coefficients for PCTSAL were reduced in size to about 2.0 but did not change in significance. UNEMP95 coefficients declined in both size and significance, with only the model three coefficient having a $p$-value below 0.10 . The PARITY coefficients became negative in models one and two but $p$-values were about 0.25 * $^{*}$

Additional models were estimated to test the sensitivity of our findings to our specification of the interaction between state mandate and/or parity laws and EMPLOYEES. First, we re-estimated all models in both Tables $\mathbf{7}$ and $\mathbf{8}$ including a dummy for each law and an interaction of that dummy with the inverse of EMPLOYEES. This did not produce evidence of substantial and significant effects for either parity or mandate laws but it did attenuate some of the HMO and EMPLOYEE coefficients. (The latter change probably reflects correlation of EMPLOYEE with the EMPLOYEE interaction terms). Using this specification for reestimating the regressions in Table 7 and excluding the single-plan employers, we did obtain significantly negative parity law effects for the smallest 10 per cent of firms (385 employees or less) but we also obtained significantly positive parity effects, that were roughly half as large, for the largest 5 per cent of firms (6763 employees or more). Since one would expect a priori that any state law effect goes to zero for the largest firms (who are most likely to self-insure), this latter result was implausible. We then reestimated the same models forcing the state law effect to go to zero by deleting the state law dummies and only including the

\footnotetext{
* Note that from a conceptual standpoint, one might argue that these results for employers offering multiple plans, as well as the results in Table 8, are subject to selection bias because the employer's choice of whether to offer one or multiple plans is endogenous.
} 


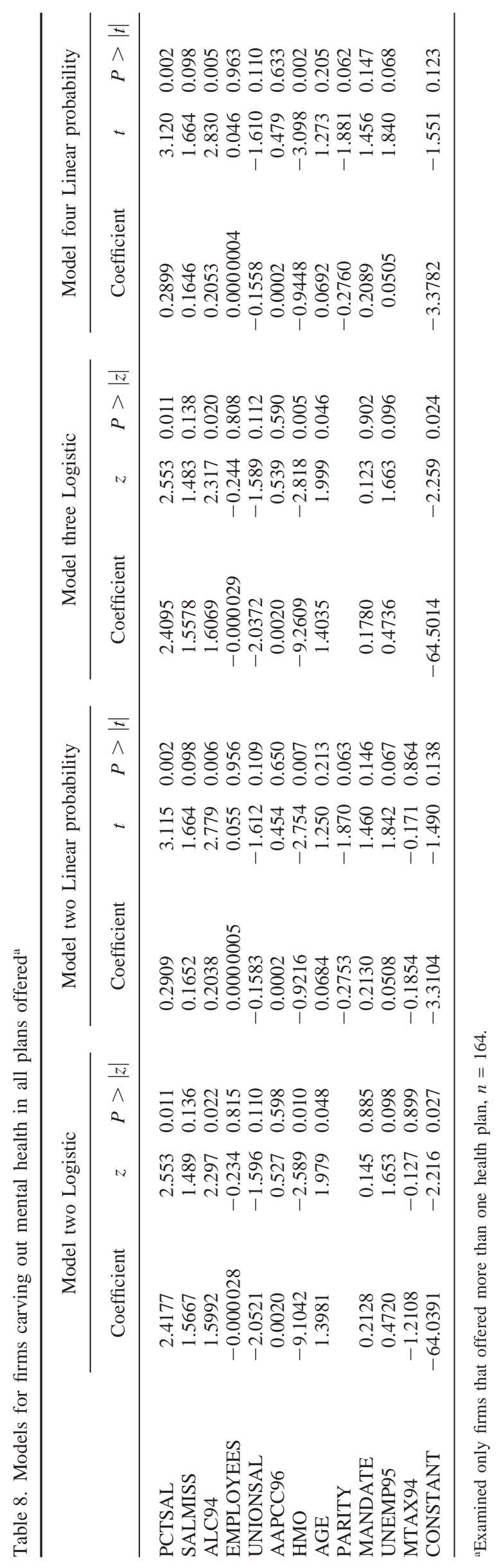


EMPLOYEE interaction terms. This did not yield any evidence of significant state law effects.

\section{Discussion}

We considered a number of different hypotheses concerning employers' demands for mental health carve-outs and found varying degrees of support for these hypotheses in our data. Our results tended to support the general cost-control hypothesis that factors associated with higher use and/or costs of mental health services increase the demand for carve-outs. The strongest evidence in this regard are the estimated coefficients for PCTSAL, ALC94 and AGE, all of which were consistently positive and often significant or nearly significant. Other variables predictive of more generous or costly benefits (PARITY, MANDATE, AAPCC96 and MTAX) often had positive coefficients but these did not approach significance. To the extent that the area unemployment rate is predictive of greater mental health utilization, the positive and significant coefficients for UNEMP95 are also consistent with this tendency. On the whole, we view this evidence as supportive of the general hypothesis that managing 'moral hazard' costs is an important function of a carve-out arrangement.

Our hypotheses concerning the role of economies of scale (i.e., group size) and the effectiveness of alternative strategies for managing moral hazard costs (i.e., HMOs) were generally supported by the results for EMPLOYEES and HMO. Also, while prior evidence suggests that unionization increases the demand for benefits, the consistently negative effect of unionization on carve-out demand in our results might be viewed as undercutting support for the basic cost-containment hypothesis. Alternatively, one might conjecture that the presence of unions leads to heightened sensitivity of unionized employees to issues of 'employer control' that could be raised by aggressive utilization management under carve-out arrangements.

Our tests of the hypothesis that carve-outs are demanded to control adverse selection were less clear in their general tendencies. We argued above that this hypothesis suggests negative coefficients for the PARITY and MANDATE variables. In fact, we only observe strongly negative PARITY coefficients in the regression on CARVEALL (Table 8). Results for the MANDATE variable are uniformly positive in all regressions and occasionally approach significance. One could attribute some of the positive effect of the EMPLOYEES variable to increased concerns over adverse selection by larger firms that tend to offer more health plan choices to employees. On the other hand, the use of a quadratic term in PCTSAL as a means to control directly for heterogeneity of the covered employees showed no impact on use of carve-outs.

It should be emphasized that, in interpreting the results for variables related to the level of mental health demand, we have assumed that these results primarily reflect moral hazard concerns per se rather than adverse selection concerns. We view this assumption as consistent with the notions that (1) adverse selection is mainly a problem of employee heterogeneity and (2) the severity of the adverse selection problem is uncorrelated with the average level of mental health demand. Of course, it is possible in some situations for an increase in the average level of demand to be distributed among covered employees in a manner that clearly results in increased heterogeneity in demand. An example would be when an increase in the average level is due entirely to an increase in the demand by high-demand employees. The reverse can also occur, however, where an increase in the average level of demand arises from higher demand by the low-demand employees, leading to reduced heterogeneity in demand. There is no reason to believe that either of these situations predominates in our data. One might also argue that, holding the degree of homogeneity in demand constant, an increase in the average level of demand increases the problem of adverse selection. This would also imply a positive link between our demand-level variables and carve-out demand due to adverse selection concerns. We are not aware, however, of data or theory that supports this particular supposition. In sum, while a positive result for some of our demand-level variables in our carve-out demand models could conceivably be due to adverse selection concerns, we view the circumstances that would lead to this result as rather unlikely. We nevertheless recognize that a sharp distinction between the moral hazard and adverse selection hypotheses is difficult to draw (as the footnote on p.85 suggests).

It is also important to note that our interpretation of our results rests on a critical assumption about the nature of the adverse selection problem. In particular, we assume that the most important inefficiency from adverse selection is the absence of high-option choices from the menu of available plans. Cutler and Reber, ${ }^{33}$ in a recent case study, estimated the cost of this inefficiency for the disappearance of a highoption general health benefit plan at about 2 per cent of premium dollars. Other researchers have argued that, in the context of managed care, the main inefficiency of adverse selection in mental health is the use by health plans of resources in their efforts to select good risks and avoid bad risks. ${ }^{34}$ (An example would be offering a free health club membership as a benefit to enrollees). We are not aware of any estimates for the costs of this type of adverse selection inefficiency.

One piece of potentially relevant evidence on the relative importance of these inefficiencies in the mental health context concerns the scope of carve-out contracts. If inefficiency due to risk selection efforts is the major consequence of adverse selection to which carve-outs are directed, one might expect single-source carve-outs (in which all employees are covered under the same mental health carve-out even though they have multiple general health options) to be common. If maintaining the viability of high-option plans is the major concern, there is less reason to expect single-source carve-outs. A recent analysis ${ }^{9}$ indicates that in fact single-source carve-outs are relatively rare. Our own data (in Table 2), and the results from Horgan et al., ${ }^{8}$ showing that the majority of employers 
offering multiple health plans do not carve out all plans, are consistent with this evidence.

Another important assumption that we have made is that the distinction between in-plan and out-of-plan carve-outs is not an important factor in the employer's choices. The logic of this assumption is that the utilization management processes used by carve-outs are attributes of a health plan that affects employer demand. This is consistent with the finding, by Hodgkin et al., ${ }^{35}$ that HMOs which contract with mental health carve-out vendors monitor the service quality provided by these vendors to ensure enrollee/purchaser satisfaction with services. Since our data did not include the contractual arrangements by which carveout services were provided, we can not directly test this assumption. This may be a fruitful subject for future empirical research.

\section{Limitations}

The evidence presented here represents an initial attempt to model employer decisions about carve-outs and, as such, should be viewed as suggestive rather than definitive. Our database includes a small number of relatively large employers and is not representative of employers nationally. Our selection criteria, concerning size and the requirement that some employees are covered by LTD insurance, probably resulted in a study sample that offers richer benefits than do employers nationally. Our employers also report a higher percentage of salaried employees relative to the national data.

A deficiency in the current study is the lack of detailed information on the socio-demographic and behavioral characteristics of covered employees. The only available datum from our survey was the percentage of employees who were salaried. Our reliance on proxy measures (such as AGE and ALC94) clearly introduces measurement error that results in less precise coefficient estimates and larger standard errors. Subsequent research with more information on covered employee characteristics will allow for a stronger test of the general hypothesis that factors associated with a higher demand for services are also associated with a higher demand for carve-outs.

Finally, the cross-sectional nature of our analysis raises concerns about susceptibility of our findings to omitted variables bias. For example, if states that passed mental health mandates and parity laws (prior to 1995) also happen to have a stronger 'taste' for use of mental health services, this will bias our estimated effects of these laws on carveout demand. Future analyses that capture the experience of states that have passed these laws more recently, and that use pooled data to control for omitted variables bias, will provide more definitive evidence on the relationship between parity laws and carve-out demand.

\section{Appendix A. Examination of Response Bias}

In view of the low response rate to the survey, the possibility that respondents may not represent all employers in the sample must be considered. We examined several sources of data to assess this possibility. First, we compared descriptive statistics pertaining to industry type, geographic region, number of employees covered in the relevant LTD contract with UNUM and numbers of claims paid under the LTD contract. These statistics were very similar for the two groups and formal statistical tests were always consistent with the null hypothesis of no differences between respondents and non-respondents.

Second, we examined possible differences between 'early' and 'late' responders. In administering the survey, we recorded information on the timeliness of response (number of days from original mailing to survey receipt) and the effort required in eliciting a response (as measured by the number of surveys that were re-mailed and by the number of follow-up phone calls). Our maintained hypothesis is that if differences were observed in behavior between 'early' and 'late' responders, this would be indicative of differences between respondents and non-respondents. We re-estimated the regressions reported in Tables $\mathbf{7}$ and $\mathbf{8}$ (above) including each of these three measures of 'lateness' (one at a time) as additional explanatory variables. None of these variables were significant in any of the models. In addition, we reestimated these regressions including each of the lateness measures (one at a time) and the interactions of these measures with all other explanatory variables in model one of Tables 7 and 8. Likelihood ratio tests on the joint significance of the coefficients for the lateness variable and all its interactions consistently and clearly supported the null hypothesis of no differences between early and late responders.

\section{Appendix B. Data Sources for Predictor Variables}

Employer characteristics such as the total number of employees (EMPLOYEES), the fraction of employees who are salaried (PCTSAL) and a dummy for union salaried employees (UNIONSAL) were obtained from the employer survey described above.* (To avoid dropping the 24 cases where PCTSAL was not reported, we included these cases with a zero value for PCTSAL and also included a dummy indicator for these cases, SALMISS.)

As a proxy for average employee age (which was not available to us), we used the mean age (AGE) for full time workers, in the industry of the employer, from the March 1996 Current Population Survey. ${ }^{36}$ The employer industry classification (SIC) was obtained from UNUM records. Where possible, the SIC code was matched to CPS data at the four-digit level, but in some cases matching was only possible at the three-digit or two-digit level. State-level variables were matched to employers by address of main

\footnotetext{
* Seventeen employers failed to report their total number of employees in the survey. To include these respondents, information on their number of employees was obtained from 1996 Dunn and Bradstreet Information Services data or from employer web sites or regional economic web sites (e.g., the Greater Toledo Regional Growth Partnership, www.rgp.org).
} 
company headquarters. Data on 1995 state unemployment rates (UNEMP95) were obtained from the Local Area Unemployment Statistics on the BLS web site. ${ }^{37}$

The 1995 per capita enrollment in health maintenance organizations (PCHMO) was obtained from the Area Resource File produced by the US Department of Health and Human Services. This county level measure was summed over the state and divided by state population to obtain state level per capita HMO enrollment. The 1996 average adjusted per capita costs (AAPCC96) for the elderly in Medicare (costs to both Part A and Part B) was obtained from the Health Care Financing Administration web site. ${ }^{38}$ Per capita alcohol consumption, in gallons, by state (ALC94) was reported by the National Institute on Alcohol Abuse and Alcoholism. ${ }^{39}$ The state marginal tax rate was calculated for 1994 based on a married couple with two dependents and earning \$40000 using state and federal tax summaries compiled by the Advisory Commission on Intergovernmental Relations. ${ }^{40}$

Data on state parity laws are published by the National Institutes of Mental Health. ${ }^{41}$ Information on state-mandated coverage of (1) mental health, (2) alcohol abuse treatment and (3) substance abuse treatment benefits was obtained from the Blue Cross and Blue Shield Association ${ }^{42}$ and compared with information from the National Conference of State Legislatures' Health Tracking service. ${ }^{43}$

\section{Acknowledgements}

Research for this paper was supported under a contract with UNUM and by National Institute of Mental Health Grant No. MH-43703 to the Center for Research on Services for Severe Mental Illness at the Johns Hopkins University. We are indebted to James Collins for assistance in preparing the manuscript and to several referees for helpful comments and suggestions.

\section{References}

1. Blumenthal D, Beeuwkes Buntin M. Carve outs: definition, experience and choice among candidate conditions. Am J Managed Care 1998; 4 (special issues): SP45-SP57.

2. American Managed Behavioral Healthcare Association. FAQs. www.ambha.org/FAQs/

3. Grazier K, Eselius L. Mental Health Carve-Outs: Effects and Implications. Med Care Res Rev 1999; 56 (suppl. 2): 37-59.

4. Buck JA, Umland B. Covering Mental Health and Substance Abuse Services. Health Affairs 1997; 16 (4): 120-126.

5. Ceniceros R. Spotlight Report: Mental Health Care: Solving the Cost Control Puzzle; Trimming Benefit Costs While Improving Care. Business Insurance, 1995, June.

6. The HayGroup. Health Care Plan Design and Cost Trends-1988 through 1998, prepared for National Association of Psychiatric Health System and Association of Behavioral Group Practices, 1999.

7. The Kaiser Family Foundation and Health Research and Educational Trust. Employer Health Benefits: 1999 Annual Survey, 1999.

8. Horgan C, Garnick D, Merrick E, Hodgkin D, Urato M, Sciegaj M, Goldin D. Fortune 500 Firms: Carve-Out Contracts with Behavioral Healthcare Vendors. Brandeis/Harvard Research Center on Managed Care and Drug Abuse Treatment, 1998.

9. Huskamp H. Episodes of Mental Health and Substance Abuse
Treatment under a Managed Behavioral Health Care Carve-Out. Inquiry 1999; 36: 147-161.

10. Volgelsang I. Economic Aspects of Mental Health Carve-Outs. $J$ Mental Health Policy Econ 1999; 2: 29-41.

11. Dowd BE, Feldman R. Voluntary Reduction in Health Insurance: a Theoretical Analysis. Eastern Econ J 1987; 13 (3): 215-212.

12. Leibowitz A, Chernew M. The Firm's Demand for Health Insurance. Health Benefits and the Workforce. USGPO: Washington, DC, 1992.

13. Jensen GA, Gabel JR. State Mandated Benefits and the Small Firm's Decision to Offer Insurance. J Regulatory Econ 1992; 4: 379-404.

14. Jensen GA, Morrisey MA. Small Group Reform and Insurance Provision by Small Firms: 1989-1995. Inquiry. 1999; 36: 176-187.

15. Morrisey MA, Jensen GA. State Mandates, Self-Insurance and Employer, Demand for Substance Abuse and Mental Health Insurance Coverage. In Advances in Health Economics and Health Services Research, vol. 14,, Scheffler and Rossiter (eds). JAI: Greenwich, CT, 1993.

16. Gentry WM, Peress E. Taxes and Fringe Benefits Offered by Employers, National Bureau of Economic Research Working Paper No. 4764, 1994.

17. Frank RG, Huskamp HA, McGuire TG, Newhouse JP. Some Economics of mental Health 'Carve-Outs'. Arch Gen Psychiatry 1996; 53: 933-937.

18. Newhouse, JP. Reimbursing Health Plans and Health Providers: Efficiency in Production versus Selection. J Econ Lit 1996; 34: 1236-1263.

19. Cutler DM, Zeckhauser RJ. Adverse Selection in Health Insurance In Frontiers in Health Policy Research, vol. 1, Garber A (ed.). MIT Press: Cambridge, 1998.

20. Price, JR, Mays, JW, Trapnell, GR. Stability in the Federal Employees Health Benefits Program. J Health Econ 1983; 2: 207-224.

21. Frank RG, McGuire TG. Economics and Mental Health. In Handbook of Health Economics, Newhouse J, Culyer A (eds). Elsevier. Amsterdam, in press.

22. Goldman WJ, McCulloch, Sturm R. Costs and Use of Mental Health Services Before and After Managed Care. Health Affairs 1998; 17(2): 40-52.

23. Sturm R. How Expensive is Unlimited Mental Health Care Coverage under Managed Care? RAND Working Paper No. 107, 1997.

24. US Census Bureau. 1997. Statistical Abstract of the United States, Table 189.

25. Leslie DL, Rosenheck R. Shifting from Inpatient to Outpatient Care? Mental Health Utilization and Costs in a Privately Insured Population. Unpublished paper, Connecticut-Massachusetts VA Mental Illness Research, Education and Clinical Center, 1998.

26. American Medical Association. 1997. Socioeconomic Characteristics of Medical Practice 1997, 83.

27. Scheffe H. A method for Judging All Contrasts in the Analysis of Variance. Biometrika 1953; 40: 87-104.

28. Uccello C. Firms Health Insurance Decisions: The Relative Effects of Firm Characteristics and State Insurance Regulation. The Urban Institute, 1996.

29. Scheffler R, Miller A. Demand Analysis of Mental Health Service Use Among Ethnic Subpopulations. Inquiry 1989; 26 (2): 202-215.

30. Keeler EB, Wells KB, Manning WG Jr, Rumpel JD, Hanley JM. The Demand for Episodes of Mental Health Services, RAND R-3432NIMH. RAND: Santa Monica, CA, 1986.

31. Wells KB, Manning WG, Jr, Duan N, Ware JE Jr, Newhouse JP Cost Sharing and the Demand for Ambulatory Mental Health Services, RAND R-2960-HHS. RAND: Santa Monica, CA, 1982.

32. Horgan C, Salkever D. 1987. The Demand for Outpatient Mental Health Care from Nonspecialty Providers. In Advances in Health Economics and Health Services Research, vol. 8, Scheffler and Rossiter (eds). JAI: Greenwich, CT, 1987.

33. Cutler DM, Reber S. Paying for Health Insurance: The Tradeoff between Competition and Adverse Selection. $Q J$ Econ 1998; 113 (2): 433-466.

34. Frank RG, McGuire TG. The Economic functions of Carve Outs in Managed Care. Am J Managed Care 1998; 4: SP31-SP44.

35. Hodgkin D, Horgan CM, Garnick DW. Make or Buy: HMOs' Contracting Arrangements for Mental Health Care. Admin Policy Mental Health 1997; 24 (4): 359-376.

36. US Bureau of Labor Statistics. March 1996 Current Population Survey. www.bls.gov

37. US. Bureau of Labor Statistics. Local Area Unemployment Statistics. www.bls.gov 
38. US Department of Health and Human Services. Health Care Financing and Administration. www.hcfa.gov

39. National Institute on Alcohol Abuse and Alcoholism (NIAAA). US Apparent Consumption of Alcoholic Beverages Based on State Sales, Taxation, or Receipt Data, 3rd edn, vol. 1. Bethesda, MD, 1997, Table 3.

40. Advisory Commission on Intergovernmental Relations (ACIR). Significant Features of Fiscal Federalism: Budget Processes and Tax System, vol. 1, M-157, 1995, Tables 6 and 19.
41. National Institute of Mental Health (NIMH). Parity in Financing Mental Health Services: Managed Care Effects on Cost, Access \& Quality, Interim report to Congress by the National Advisory Mental Health Council. Bethesda, MD, 1998, Appendix D.

42. Blue Cross and Blue Shield Association. State Mandated Benefits and Providers. Unpublished report, 1996.

43. National Conference of State Legislatures web site. www.ncsl.gov 